\title{
Obstetrical outcome in post caesarean pregnancy
}

\author{
Anitha Aldur Manjappa ${ }^{1 *}$, Soundara Raghavan Subrahmanian²
}

\begin{abstract}
${ }^{1}$ Department of Obstetrics and Gynecology, ESIC Medical College and PGIMSR, Chennai, Tamil Nadu, India
${ }^{2}$ Department of Obstetrics and Gynaecology, JIPMER, Puducherry, India
\end{abstract}

Received: 22 August 2018

Accepted: 27 September 2018

\section{*Correspondence:}

Dr. Anitha Aldur Manjappa,

E-mail: dr_ani1999@yahoo.com

Copyright: ( ) the author(s), publisher and licensee Medip Academy. This is an open-access article distributed under the terms of the Creative Commons Attribution Non-Commercial License, which permits unrestricted non-commercial use, distribution, and reproduction in any medium, provided the original work is properly cited.

\begin{abstract}
Background: Rates of caesarean delivery have increased over past 40 years. The increase has been attributed to liberalization of indications for caesarean sections. Repeat caesarean section is a major contributor to caesarean rates; Vaginal Birth After Caesarean (VBAC) is one of the methods to contain increasing caesarean rates. Success rates of $60-80 \%$ have been reported.

Methods: This was a descriptive study involving 1000 pregnancies of period of gestation more than 28 weeks with history of one previous caesarean section. The women under study were subjected to either trial vaginal delivery or elective repeat caesarean delivery depending upon the clinical situation. The percentage of successful vaginal deliveries, factors responsible for failure of vaginal delivery and differences in outcome between successful vaginal delivery and caesarean delivery group were analyzed.

Results: Out of the 1000 women, 423 underwent elective repeat caesarean delivery, of the remaining 577, 403 $(69.8 \%)$ had successful vaginal delivery. Age of the woman and onset of labour were the only factors influencing the success of vaginal delivery. Women aged 35 years or more and women who needed labour induction had lower success of vaginal delivery. Maternal and perinatal outcome were worse in failed vaginal delivery group when compared to elective repeat caesarean delivery or successful vaginal delivery groups.

Conclusions: Factors which are usually thought to influence the decision about trial vaginal delivery like prior vaginal delivery, indication for previous caesarean section and interpregnancy interval are not absolute in determining the decision or the outcome. Labour induction should be resorted with great caution in women with post caesarean pregnancy.
\end{abstract}

Keywords: Previous caesarean pregnancy, Trial of vaginal delivery, Vaginal birth after caesarean section

\section{INTRODUCTION}

Caesarean section is the most common obstetric procedure practiced now a day. World Health Organization recommendation is to achieve an ideal caesarean section rate of $10-15 \%$, in-spite the rates of caesarean section has been increasing both in developed and developing countries. ${ }^{1,2}$ Repeat caesarean section is a major contributor to the raising caesarean rates. ${ }^{3}$ It has been observed that caesarean sections as like any surgery, is associated with short and long term risk which can affect maternal, fetal health and future pregnancy outcome. ${ }^{4,5}$ These risks are higher in women with limited access to comprehensive obstetric care. As per WHO's statement on caesarean section rates, at population level caesarean section rates higher than $10 \%$ are not associated with reductions in maternal and neonatal mortality rates and concludes that caesarean section should be performed only for medically indicated reasons. ${ }^{6}$ In India caesarean section rate continues to be 
high, caesarean section rates in the public, charitable and private sectors were found to be $20 \%, 38 \%$ and $47 \%$ respectively. ${ }^{7}$ Consequently increasing number of women present with post caesarean pregnancy, face the issue of mode of delivery. Vaginal Birth After Caesarean (VBAC) is one of the methods to contain increasing caesarean rates.

There is a consensus National Institute for Health and Care Excellence (NICE), Royal College of Obstetricians and Gynaecologists (RCOG), American College of Obstetricians and Gynecologists (ACOG) and National Institutes of Health (NIH) that planned VBAC is a clinically safe choice for the majority of women with a single prior lower segment caesarean section, such a strategy is also supported by health economic modelling. ${ }^{8}$

In spite of numerous studies claiming higher success rates of VBAC (60-80\%) and guidelines set by ACOG (1999), the rates of VBAC continue to be low. ${ }^{9,10}$ However an apparent increase in the frequency of uterine rupture and concern about the maternal and perinatal morbidity have challenged the safety and appropriateness of VBAC. ${ }^{11}$

ACOG in 2017 recommended that almost all women with previous one low transverse caesarean section are candidates for trial of labour and they should be counseled regarding option for Trial of Labour After Caesarean Section (TOLAC) and Elective Repeat Caesarean Delivery (ERCD). ${ }^{12}$

The primary objective of the study was to analyze the percentage of success of vaginal delivery in the group planned for VBAC and to identify the factors which contributed to failure of vaginal delivery. Secondary objective was to compare the maternal and perinatal outcome between successful VBAC group, failed VBAC group and ERCD group.

\section{METHODS}

This was a descriptive study involving 1000 pregnancies of period of gestation more than 28 weeks with history of one previous caesarean section admitted to JIPMER, Puducherry. Study was performed for the period of two years. The study was approved by the institute research committee and the institute ethical committee. Pregnant women with previous two or more caesarean delivery, history of myomectomy and classical caesarean section were excluded from the study.

Being a retrospective study, the details regarding personal information, previous obstetric history and present pregnancy details were obtained from medical records. The decision for elective repeat caesarean or vaginal delivery was made as per the protocol followed in the department. Women planned for repeat caesarean were operated electively. Women with a nonrecurrent indication in the previous section, no definite reason to suspect scar integrity and with cephalic presentation in this pregnancy were decided for trial vaginal birth. Labour induction was done for obstetrical indications. During labour women were carefully monitored and labour was terminated by caesarean section when fetal heart rate abnormality, scar rupture or any other labour abnormalities were detected.

Variables such as age of the women, previous vaginal delivery, previous caesarean indication, interpregnancy interval and mode of onset of labour were studied on its relation to VBAC success. Maternal and perinatal outcome data obtained were used in analysis and comparison between three groups involved in the study.

The statistical analysis was using chi square test for all variables. The statistical significance was considered when $(\mathrm{p}=<0.05)$. The numerical data were expressed as mean \pm SD.

\section{RESULTS}

Out of the 1000 women included in the study, 423 $(42.3 \%)$ were planned for elective repeat caesarean delivery (group A). The remaining 577 (57.7\%) women were considered for trial of vaginal delivery. Among the 577 women where trial vaginal delivery was attempted $403(69.8 \%)$ had successful trial (Group B). The remaining $174(30.2 \%)$ underwent repeat caesarean section thus forming the failed trial vaginal delivery group (Group C). This is illustrated in Table 1.

Table 1: Outcome in the entire study group.

\begin{tabular}{|lc|}
\hline $\begin{array}{l}\text { Total women studied } \\
\text { (Group A) }\end{array}$ & $1000(\%)$ \\
\hline $\begin{array}{l}\text { Women subjected to trial vaginal } \\
\text { delivery }\end{array}$ & $423(42.3)$ \\
\hline $\begin{array}{l}\text { Successful trial vaginal delivery } \\
\text { (Group B) }\end{array}$ & $577(57.7)$ \\
\hline Failed trial vaginal delivery (Group C) & $174(17.4)$ \\
\hline
\end{tabular}

There are many variables studied so far in prediction of VBAC success. In present study we have studied in relation of age, previous vaginal delivery, indication for previous caesarean section, interpregnancy interval and mode of onset of labour in prediction of VBAC. It is shown in Table 2, 3. The average age among the women studied was 25 years $(25.01 \pm 3.380)$. The age distribution among the 3 groups was similar, the mean age being $25.02 \pm 3.42,25 \pm 3.34$ and $25.02 \pm 3.37$ in group A, B, C respectively. Nineteen $(1.9 \%)$ women were 35 years or older. Among them, eleven $(57.9 \%)$ of them had a trial for vaginal delivery but only five $(26.3 \%)$ of them delivered successfully, making the caesarean section rate of $73.7 \%$. Success rate of vaginal delivery in women aged less than 35years was high $70.3 \%$ when compared to $45.5 \%$ in women $\geq 35$ years. It was significant $(\mathrm{p}=0.0006)$. 
Table 2: Variables studied in the study group.

\begin{tabular}{|c|c|c|c|c|c|}
\hline Variables & & $\begin{array}{l}\text { Elective repeat } \\
\text { caesarean delivery } \\
\text { Group A (423) (\%) }\end{array}$ & $\begin{array}{l}\text { Successful trial } \\
\text { vaginal delivery } \\
\text { Group B (403) (\%) }\end{array}$ & $\begin{array}{l}\text { Failed trial vaginal } \\
\text { delivery } \\
\text { Group C (174) (\%) }\end{array}$ & Total \\
\hline \multirow{4}{*}{ Age in years } & $\leq 19$ & $4(57.1)$ & $3(42.9)$ & 0 & 7 \\
\hline & $20-29$ & $372(42.2)$ & $352(39.9)$ & $157(17.8)$ & 881 \\
\hline & $30-34$ & 39 (41.9) & $43(46.2)$ & $11(11.8)$ & 93 \\
\hline & $\geq 35$ & $8(42.1)$ & $5(26.3)$ & $6(31.6)$ & 19 \\
\hline \multirow{3}{*}{$\begin{array}{l}\text { Number of prior } \\
\text { vaginal delivery }\end{array}$} & --- & $359(42.4)$ & $335(39.6)$ & $152(18)$ & 846 \\
\hline & One & $51(39.5)$ & $61(47.3)$ & $17(13.2)$ & 129 \\
\hline & Two & $13(52)$ & $7(28)$ & $5(20)$ & 25 \\
\hline \multirow{2}{*}{$\begin{array}{l}\text { Indication for previous } \\
\text { caesarean section }\end{array}$} & Recurrent & 137(53.1) & $86(33.3)$ & $35(13.5)$ & 258 \\
\hline & Non-recurrent & $286(38.5)$ & $317(42.7)$ & $139(18.7)$ & 742 \\
\hline \multirow{2}{*}{$\begin{array}{l}\text { Interval between } \\
\text { current pregnancy and } \\
\text { previous caesarean }\end{array}$} & $\leq 18$ months & $51(39.5)$ & $56(43.4)$ & $22(17.1)$ & 129 \\
\hline & $>18$ months & $372(42.7)$ & $347(39.8)$ & $152(17.4)$ & 871 \\
\hline \multirow{2}{*}{ Labour onset } & Spontaneous & & $368(73.3 \%)$ & 134 & $\begin{array}{l}\text { n577 } \\
502\end{array}$ \\
\hline & Induced & & $35(46.7 \%)$ & 40 & 75 \\
\hline
\end{tabular}

Table 3: Effect of variables on prediction of VBAC (n-577).

\begin{tabular}{|c|c|c|c|c|c|}
\hline Factor & & No. & $\begin{array}{l}\text { No. of } \\
\text { successful trial }\end{array}$ & Percentage & Significance \\
\hline \multirow[b]{2}{*}{ Age } & $<35$ & 566 & 398 & 70.3 & \multirow{2}{*}{$S, p=0.0006$} \\
\hline & $\geq 35$ & 11 & 5 & 45.5 & \\
\hline \multirow{2}{*}{ Previous vaginal delivery } & Yes & 90 & 68 & 75.6 & \multirow{2}{*}{$\mathrm{NS}, \mathrm{p}=0.342$} \\
\hline & No & 487 & 335 & 68.8 & \\
\hline \multirow{2}{*}{ Indication for previous caesarean section } & Recurrent & 121 & 86 & 71.1 & \multirow{2}{*}{$\mathrm{NS}, \mathrm{p}=1.000$} \\
\hline & Nonrecurrent & 456 & 317 & 69.5 & \\
\hline \multirow{2}{*}{ Interpregnancy interval } & $\leq 18$ months & 78 & 56 & 71.8 & \multirow{2}{*}{$\mathrm{NS}, \mathrm{p}=0.876$} \\
\hline & $>18$ months & 499 & 347 & 69.5 & \\
\hline \multirow{2}{*}{ Onset of labour } & Spontaneous & 502 & 368 & 73.3 & \multirow{2}{*}{$S, p=0.003$} \\
\hline & Induced & 75 & 35 & 46.7 & \\
\hline
\end{tabular}

Among the 1000 women in study group, 154 (15.4\%) had one or more vaginal deliveries either before or after caesarean section. Sixty-four $(41.6 \%)$ out of 154 with prior vaginal birth were planned for elective repeat caesarean delivery and this was not different from the overall elective repeat caesarean delivery rate $(42.3 \%)$. $(\mathrm{p}=0.425)$. So, in present study decision for elective repeat caesarean delivery or trial of labour was not influenced by prior vaginal delivery. $39.5 \%$ of women with one prior vaginal delivery were planned for elective repeat caesarean delivery when compared to $52 \%$ of women with previous two vaginal deliveries. This was because most of the women had pregnancy related complications such as preeclampsia, gestational diabetes mellitus, oligohydramnnios with or without previous living issue and these women were directly planned for caesarean delivery.

Among the 90 women, with history of one or two vaginal delivery when planned for trial vaginal birth, 68 (75.6\%) had a successful trial vaginal delivery. This figure was
$78.2 \%$ with one prior vaginal birth when compared to $58.3 \%$ women with two prior vaginal births. This difference was statistically significant $(\mathrm{p}=0.003)$. This was a surprising finding because one would have expected more successful vaginal deliveries with more prior vaginal deliveries. This was because majority had fetal distress during the course of labour and pregnancy was terminated by emergency caesarean section.

Other causes were suspected scar dehiscence and failed induction. Again, $68.8 \%$ women with no history of prior vaginal delivery had successful trial compared to $75.6 \%$ with history of prior vaginal delivery $(\mathrm{p}=0.342)$.

In the present study, 258 (25.8\%) women had recurrent indications in the previous caesarean section and $742(74.2 \%)$ had non-recurrent indication. The success of trial vaginal among non-recurrent group was $69.5 \%$ not very different from the women who had recurrent indications $71.1 \% \quad(p=1.0000)$. The non-recurrent indications in the previous caesarean section are shown in 
the Table 4. When fetal distress, malpresentation or failed inductions were the indications in previous caesarean section, $64-75 \%$ of planned vaginal deliveries were successful.

Table 4: Non-recurrent indications in previous caesarean delivery.

\begin{tabular}{|c|c|c|c|c|}
\hline Variables & $\begin{array}{l}\text { Elective repeat caesarean } \\
\text { delivery Group A (423) }\end{array}$ & $\begin{array}{l}\text { Successful trial vaginal } \\
\text { delivery Group B (403) }\end{array}$ & $\begin{array}{l}\text { Failed trial vaginal } \\
\text { delivery Group C (174) }\end{array}$ & Total \\
\hline Fetal distress & 113 & $134(64.4 \%)$ & 74 & 321 \\
\hline Malpresentation & 84 & $68(74.7 \%)$ & 23 & 175 \\
\hline Oligohydramnnios & 9 & 9 & 8 & 26 \\
\hline Post term & 5 & 6 & 2 & 13 \\
\hline Cord prolapse & 4 & 6 & 1 & 11 \\
\hline $\mathrm{APH}$ & 10 & 11 & 1 & 22 \\
\hline Multiple pregnancy & 6 & 8 & 0 & 14 \\
\hline Hypertensive disorder & 5 & 9 & 4 & 18 \\
\hline Failed induction & 34 & $46(68.6)$ & 21 & 101 \\
\hline Not known & 16 & 20 & 5 & 41 \\
\hline
\end{tabular}

In the present study, 129 women had the previous caesarean section within 18 months of current pregnancy. Out of these, $78(60.5 \%)$ were planned for vaginal delivery and the success rate among these was $71.8 \%$. Among the 871 women who had an interval of more than 18 months, $499(57.3 \%)$ were planned for vaginal delivery. Successful trial was achieved in $69.5 \%$. $(\mathrm{p}=0.876)$.

Among the 1000 women in study, 577 women planned for TOLAC. $502(87 \%)$ had spontaneous onset of labour. Among these, $368(73.3 \%)$ had successful trial. In $75(13 \%)$ women in whom labour induction was done, trial vaginal delivery was successful in only 35 women $(46.7 \%)$. The difference in success rate between the spontaneous labour and induction group was significant. $(\mathrm{p}=0.003)$. Among the 502 women who had spontaneous onset of labour, incidence of scar dehiscence was 2.19 $\%$ in the spontaneous labour group. Among the 75 women who had labour induction, one scar dehiscence was found at caesarean section $(1.33 \%)$.

The difference in incidence of scar dehiscence between spontaneous labour and induced labour was not statistically significant $(\mathrm{p}=1.000)$. The above findings are summarized in the Table 5 There were 20 instances (2\%) of uterine rupture in this study. Sixteen of them $(80 \%)$ were in the spontaneous labour onset group, accounting for $3.18 \%$. Four of the rupture uterus occurred in labour induction group $(5.33 \%)$. The difference was not statistically significant $(\mathrm{p}=0.722)$.

Table 5: Labour onset and scar dehiscence or rupture.

\begin{tabular}{|lll|}
\hline Labour onset & Dehiscence & Rupture \\
\hline Spontaneous (n-502) & $11(2.19 \%)$ & $16(3.18 \%)$ \\
\hline Induced (n-75) & $1(1.33 \%)$ & $4(5.33 \%)$ \\
\hline
\end{tabular}

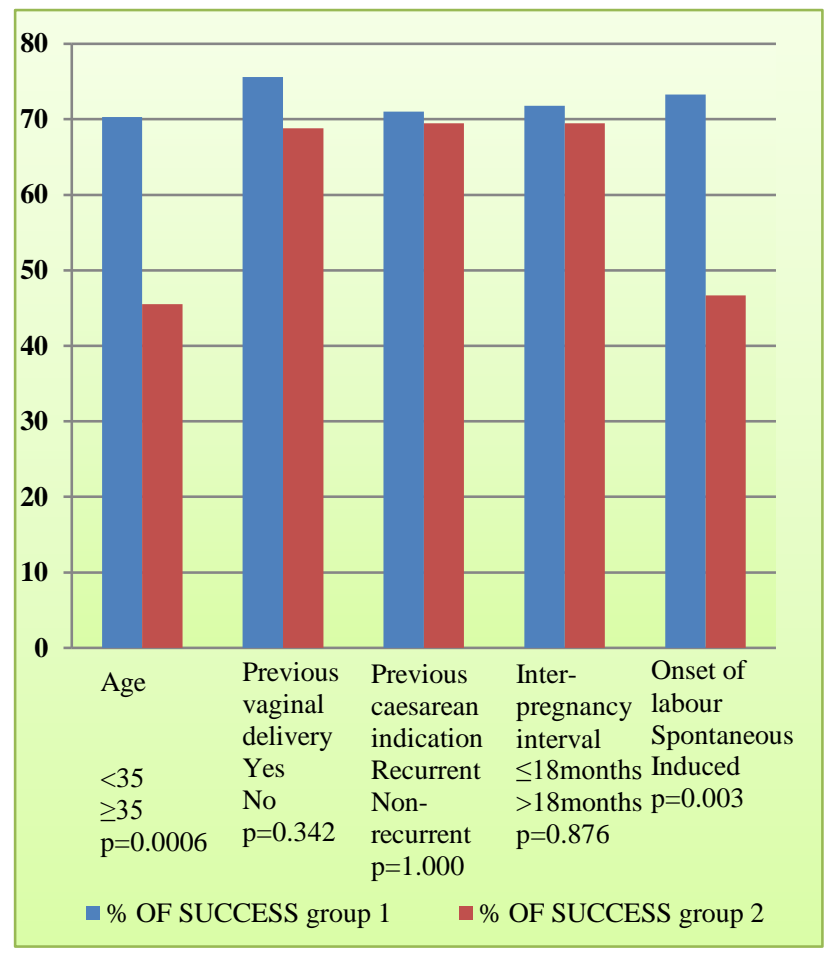

Figure 1: Variables associated with successful vaginal delivery and its p value.

Among the 403 women in successful vaginal group, 288 $(71.5 \%)$ delivered spontaneously. There were 115 operative vaginal deliveries. Ventouse was the most common method (14.9\%) followed by forceps delivery in $13 \%$ of the women. There were $3(0.7 \%)$ breech deliveries. One woman had severe preeclampsia therefore pregnancy was terminated. She delivered an IUGR fetus weighing $1.02 \mathrm{~kg}$. Baby expired in NICU one day later. There were two undiagnosed breech deliveries. Both of them came late in labour and had assisted breech 
deliveries without any maternal or perinatal complications. Among the 577 women in whom vaginal delivery was planned, abdominal delivery had to be done in $174(30.2 \%)$. The major reason for this was fetal distress in $40.2 \%$ women. Other indications being suspected Scar dehiscence or rupture (27.5\%), Cephalopelvic disproportion $(10.9 \%)$, failed induction $(14.9 \%)$, non-progress of labour $(5.7 \%)$ and cord prolapse in one $(0.6 \%)$ women.

In the present study previous vaginal delivery, indication for previous caesarean section, interval between previous caesarean section and current pregnancy were the factors which were not found to influence the success of vaginal delivery. Age less than thirty-five years and spontaneous labour onset were the factors which were found to positively influence the success of vaginal delivery. It has been depicted in Figure 1.

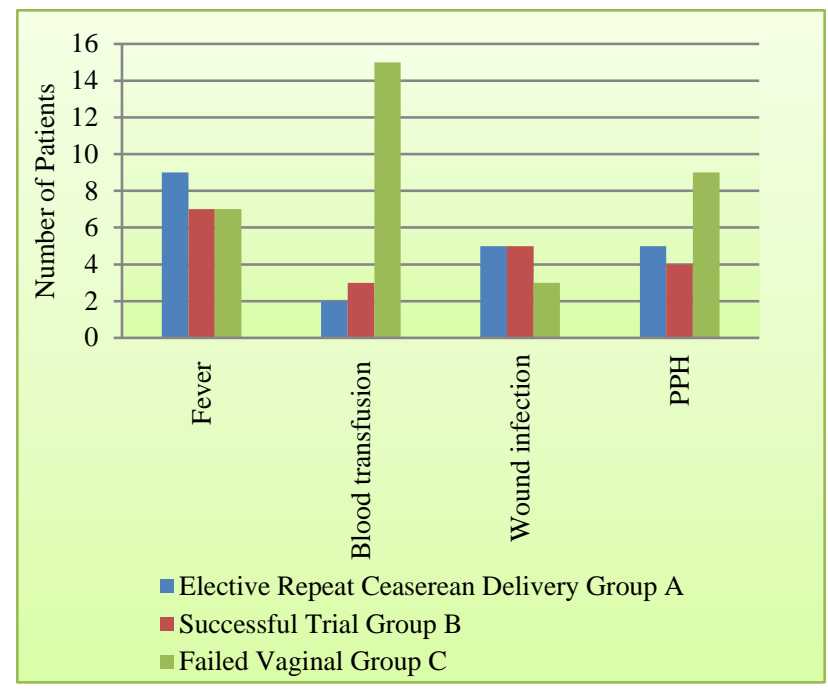

Figure 2: Maternal complications.

Maternal Outcome; There was no maternal mortality in this study. Seventy-four women (7.4\%) had some morbidity or other. Table 6 shows the various maternal complications. Febrile morbidity was more in the elective repeat caesarean delivery group when compared to successful trial vaginal delivery but need for blood transfusion and $\mathrm{PPH}$ was more in failed trial vaginal group. Wound sepsis was similar in the elective repeat caesarean delivery and successful trial vaginal groups.
Maximum maternal complications were in the group of women with failed vaginal delivery, when compared to those who had elective repeat caesarean delivery or successful vaginal delivery. It was statistically significant $(\mathrm{p}=0.0000)$. Overall maternal complications studied are depicted in the Figure 2.

Perinatal Outcome; There were $26(2.6 \%)$ perinatal deaths in the study. It constituted about $3(0.71 \%)$ perinatal deaths in the elective repeat caesarean delivery group, compared with $6(1.48 \%)$ in the successful vaginal delivery group and $17(9.77 \%)$ in the failed vaginal delivery group.

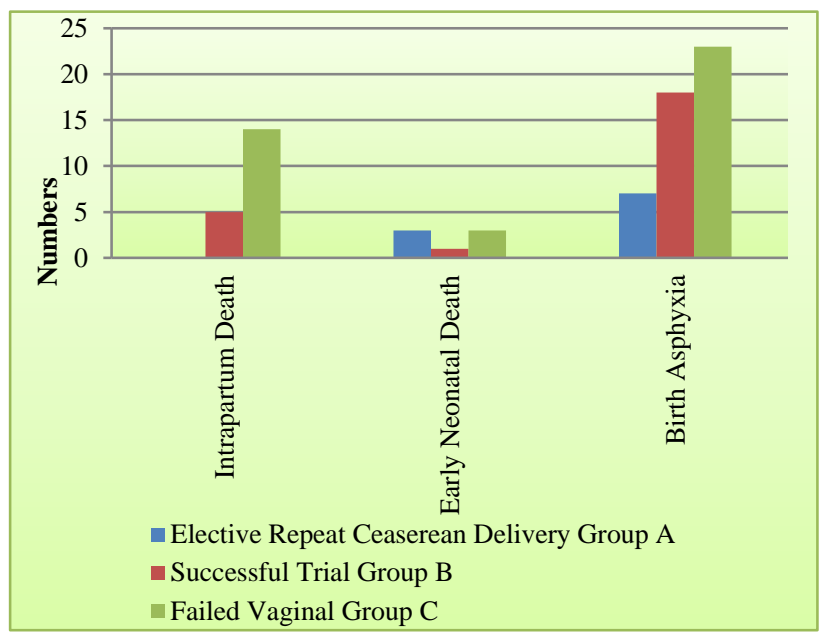

Figure 3: Perinatal outcome.

Need for NICU admission was 5\% in the present study. Birth asphyxia constituted the major factor. It accounted for $13.2 \%$ in failed vaginal delivery group, compared to $1.6 \%$ in elective repeat caesarean delivery group and $4.4 \%$ in successful vaginal delivery group. Other causes for NICU admission were congenital anomaly (Rocker bottom feet) and pelviureteral junction obstruction in two neonates in the successful vaginal delivery group. And overall mean duration of NICU stay was 3.52 \pm 3.36 days. It is shown in Table 7 . When comparing perinatal complications between the successful vaginal and the failed vaginal groups, it was more common in failed vaginal delivery group. $(\mathrm{p}=0.0001)$. It was significant again when comparing perinatal complications between successful vaginal with failed vaginal and elective repeat caesarean delivery group $(\mathrm{p}=0.021)$.

Table 6: Maternal complications.

\begin{tabular}{|llll|}
\multicolumn{1}{|c}{ Variables } & $\begin{array}{l}\text { Elective repeat } \\
\text { caesarean delivery } \\
\text { Group A }(\mathbf{4 2 3})\end{array}$ & $\begin{array}{l}\text { Successful trial } \\
\text { vaginal delivery } \\
\text { Group B (403) }\end{array}$ & $\begin{array}{l}\text { Failed trial } \\
\text { vaginal delivery } \\
\text { Group C (174) }\end{array}$ \\
\hline Fever (n-23) & $9(2.1 \%)$ & $7(1.7 \%)$ & $7(4 \%)$ \\
\hline Blood transfusion (n-20) & $2(0.5 \%)$ & $3(0.7 \%)$ & $15(8.6 \%)$ \\
\hline Wound infection (abdominal/perineal) $(\mathrm{n}-13)$ & $5(1.2 \%)$ & $5(1.2 \%)$ & $3(1.7 \%)$ \\
\hline Postpartum haemorrhage (PPH)(n-18) & $5(1.2 \%)$ & $4(1 \%)$ & $9(5.2 \%)$ \\
\hline
\end{tabular}


Table 7: Perinatal outcome.

\begin{tabular}{|llll|}
\hline \multicolumn{1}{|c|}{ Variables } & $\begin{array}{l}\text { Elective repeat caesarean } \\
\text { delivery Group A (423) }\end{array}$ & $\begin{array}{l}\text { Successful trial vaginal } \\
\text { delivery Group B (403) }\end{array}$ & $\begin{array}{l}\text { Failed trial vaginal } \\
\text { delivery Group C (174) }\end{array}$ \\
\hline Intrapartum death (n-19) & - & $5(1.23 \%)$ & $14(8.04 \%)$ \\
\hline Early neonatal death (n-7) & $3(0.71 \%)$ & $1(0.23 \%)$ & $3(1.71 \%)$ \\
\hline Birth asphyxia (n-48) & $7(1.65 \%)$ & $18(4.46 \%)$ & $23(13.2 \%)$ \\
\hline NICU duration days (mean) $3.52 \pm 3.36$ & $2 \pm 0.75$ & $3.05 \pm 2.27$ & $4.41 \pm 4.3$ \\
\hline
\end{tabular}

\section{DISCUSSION}

VBAC success rate depends mainly on the demographic and obstetric characteristics of the pregnant women. It has been observed that, women with successful VBAC have favorable outcome in terms of the decrease in incidence of maternal and fetal morbidity when compared to women with failed VBAC. ${ }^{12}$ In the present study the overall success rate of VBAC was 69.8, which is comparable to success rate obtained by many researches. ACOG 2010 quoted success rate of $60-80 \% .^{13}$ VBAC success rate also vary between institutions and service provider. It is worth remarking that there is no reliable and demonstrable algorithms or nomograms that always correctly identifies or accurately predicts successful VBAC. ${ }^{14}$ Therefore management of a case of previous caesarean continues to be an obstetrical dilemma.

In the present study, average age in successful vaginal delivery, failed vaginal delivery and elective repeat caesarean delivery group was 25 years. Researchers have found higher failure rate of vaginal delivery in women more than 35 years of age. It was comparable to present study, which showed failure rate of VBAC of about $54.5 \%$ in women above 35 years of age. ${ }^{15,16}$

The observed success rate of vaginal delivery in present study in patients with one or more prior vaginal delivery was $75.6 \%$ compared to $68.8 \%$ in patients without prior vaginal delivery. In present study previous vaginal delivery in prediction of VBAC success was not significant. Success rate of about $85-90 \%$ has been reported in women with one or more prior vaginal delivery. ${ }^{8}$ Landon et al, reported $86.6 \%$ success rate in women with previous vaginal delivery compared with $60.9 \%$ in women without such a history. ${ }^{17}$

In present study overall success rate of VBAC observed was $69.8 \%$. It was $69.5 \%$ for nonrecurrent indications compared to $71.1 \%$ for recurrent indications. Researches have shown success rate of VBAC upto $90 \%$ for nonrecurrent indications and $60 \%$ for recurrent indications. ${ }^{18,19}$

Landon et al reported successful VBAC was more likely among women with previous caesarean for fetal malpresentation (84\%) compared with women with previous caesarean for either labour dystocia (64\%) or fetal distress $(73 \%)$ indication. ${ }^{17}$ Present study showed success rate of $74.7 \%$ for fetal malpresentation, $71.1 \%$ for labour dystocia and $64.4 \%$ for fetal distress as an indication for previous caesarean delivery. Success rate of VBAC was similar to recurrent and nonrecurrent indications in the present study. This might be because recurrent indications were over diagnosed in the previous pregnancy and hence definite protocol should be considered while diagnosing recurrent indications during labour.

In the present study, success rate of vaginal delivery was $71.8 \%$ in patients with interpregnancy interval less than or equal to 18 months when compared to $69.5 \%$ in patients with interpregnancy interval more than 18 months. Haung et al observed the VBAC success rate was $79.0 \%$ for patients with an interdelivery interval less than 19 months compared with $85.5 \%$ for patients with an interdelivery interval greater than or equal to 19 months. ${ }^{20}$ In a study by Bujold an interdelivery interval shorter than 18 months was associated with an increased risk of uterine rupture. ${ }^{21}$ conversely in a study by Kessous, they observed shorter inter-delivery interval was not a risk factor for complications such as uterine rupture. ${ }^{22}$

In the present study success rate observed for women with spontaneous onset of labour was $73.3 \%$ compared to $46.7 \%$ for whom labour was induced. AHRQ metaanalysis showed success of $74 \%$ in spontaneous group and $63 \%$ in induced group. ${ }^{23}$ Australian population study has reported VBAC success rate of $52.6 \%$ and $51.4 \%$ respectively in spontaneous and induced delivery group. ${ }^{24}$ In present study success rate of VBAC was less for women in induced delivery group. It suggests spontaneous onset of labour should always be awaited while considering women for VBAC.

Uterine rupture rate was $3.18 \%$ in spontaneous delivery group compared to $5.33 \%$ in induced delivery group. AHRQ metaanalysis observed $0.47 \%$ and $1.2 \%$ uterine rupture rate in spontaneous and induced delivery group respectively. ${ }^{23}$ Australian population study and a case control study by UK have obtained similar results. Induced labour increases the risk of uterine rupture and the decision should be taken very carefully and monitoring during labour should be more vigilant. ${ }^{24,25}$

Among 577 women in trial vaginal delivery group, 174 women had failed vaginal delivery resulting in 
emergency caesarean delivery accounting to $30.2 \%$. Most common cause was fetal distress $(40.2 \%)$, followed by suspected scar integrity accounting to $17.2 \%$. This finding was similar to a study by Latika et al where fetal distress was the most common indication of repeat emergency caesarean section followed by scar tenderness. ${ }^{26}$

In a study by Thapsamuthdechakorn et al observed, women changing their mind during course of labour (no obvious obstetric indications) in $43.04 \%$ cases, Dystocia $(29.53 \%)$, failed induction $(12.66 \%)$, Non-reassuring fetal heart rate in $(8.86 \%)$ women. ${ }^{27}$

A recent study reported that the commonest indication of emergency repeat caesarean delivery was non-progress of labour in $44(34.37 \%)$ women. Other were impending rupture $(28.12 \%)$, fetal distress $(17.18 \%)$ and meconium stained liquor $(15.62 \%)$ women. ${ }^{28}$ In a study by Mishra et al, the most common indications for repeat emergency caesarean section were non-progress of labour and failed induction of labour. ${ }^{29}$

\section{Maternal and perinatal outcome}

In the present study, there were no maternal deaths, a finding similar to that reported by Latika et al and Jain R. ${ }^{28}$ AHRQ meta-analysis showed an increased risk of maternal mortality with ERCD compared with planned VBAC (13/100 000 versus 4/100 000). ${ }^{23,26}$ Maternal morbidity was studied in terms of febrile morbidity, blood transfusion, abdominal wound infection, perineal wound infections and post-partum haemorrhage. Overall it was seen in $7.4 \%$ of women.

In the present study maternal morbidity was higher in women under failed vaginal delivery and it was statistically significant ( $\mathrm{p}$ value-0.0000). It was similar to observations reported by other studies. ${ }^{29,30}$ Conversely AHRQ meta-analysis reported occurrence of maternal complications such as hysterectomy, thromboembolic disease, transfusion and endometritis did not differ significantly between planned VBAC and ERCD. ${ }^{23} \mathrm{~A}$ review by Maternal-Fetal Medicine Units Network publications, concludes that women undergoing VBAC as compared with ERCD have a significantly increased incidence of blood transfusion, but the risk of hysterectomy is not increased. ${ }^{31}$ Overall perinatal complications were more common in the failed vaginal delivery group $(\mathrm{p}=0.0000)$. In present study perinatal mortality was $9.77 \%$ in women with failed VBAC compared to $0.71 \%$ in patients of elective repeat caesarean delivery group.

Crowther CA et al, reported threefold increase in risk of perinatal mortality, birth asphyxia, NICU admission and other complications in planned VBAC group compared with infants in the ERCD group. ${ }^{32}$ A review by Maternal-Fetal Medicine Units Network publications observed similar rates of neonatal seizures and perinatal mortality between women undergoing VBAC and ERCD. ${ }^{31}$ Admission to NICU was $5.0 \%$ in study group. Birth asphyxia was most common, it was more common in the failed vaginal delivery group $(13.2 \%)$ compared to $4.4 \%$ and $1.6 \%$ in the successful vaginal delivery group and the elective repeat caesarean delivery group respectively. A study by Jain $\mathrm{R}$. reported, admission rate to neonatal intensive care unit was less in successful $\operatorname{VBAC}(2.77 \%)$ than failed vaginal group $(7.03 \%){ }^{29}$

\section{CONCLUSION}

In the context of containing the increasing rates of caesarean sections, there is a definite scope for vaginal delivery after caesarean section. Factors which are usually thought to influence the decision about trial vaginal delivery like prior delivery, indication for previous caesarean section and interval from previous caesarean section are not absolute in determining the decision or the outcome. Maternal age over 35 years and labour induction are the factors which definitely reduce the probability of successful vaginal delivery. Both maternal and perinatal risks are increased when a trial of vaginal delivery fails. So, a more liberal selection may be done for planned caesarean section in such circumstances.

\section{ACKNOWLEDGMENTS}

Authors would like to thank Dr. Jayalakshmi and staff of Medical Records Department for their support during the study.

Funding: No funding sources

Conflict of interest: None declared

Ethical approval: The study was approved by the Institutional Ethics Committee

\section{REFERENCES}

1. Vogel JP, Betrán AP, Vindevoghel N, Souza JP, Torloni MR, Zhang $\mathrm{J}$ et al. on behalf of the WHO Multi-Coun $\operatorname{try}$ Survey on Maternal and Newborn Health Research Network. Use of the Robson classification to assess caesarean section trends in 21 countries: a secondary analysis of two WHO multicountry surveys. Lancet Global Health 2015;3(5):e260-70.

2. Ye J, Betran AP, Vela MG, Souza JP, Zhang J. Searching for the Optimal Rate of Medically Necessary Caesarean Delivery. Birth. 2014;41(3):237-43.

3. Rosenstein MG, Kuppermann M, Gregorich SE, Cottrell EK, Caughey AB, Cheng YW. Association between Vaginal Birth after Caesarean Delivery and Primary Caesarean Delivery Rates. Obstet Gynecol 2013;122(5):1010.

4. Lumbiganon P, Laopaiboon M, Gulmezoglu AM, Souza JP, Taneepanichskul S, Ruyan P, et al: Method of delivery and pregnancy outcomes in Asia: the WHO 
global survey on maternal and perinatal health 2007 08. Lancet. 2010;375(9713):490-9.

5. Villar J, Carroli G, Zavaleta N, Donner A, Wojdyla D, Faundes A, et al. Maternal and neonatal indivi $\neg$ dual risks and benefits associated with caesarean delivery: multicentre prospective study. BMJ. 2007;335(7628):1025.

6. WHO Statement on Caesarean Section Rates - World Health Organization Available at who.int/iris/bitstream/10665/161442/1/WHO_RHR_15. 02_eng.pdf.

7. Sreevidya S, Sathiyasekaran BW: High caesarean rates in Madras (India): a population-based cross-sectional study. BJOG. 2003;110(2):106-11

8. Royal College of Obstetricians and Gynaecologists. Birth After Previous Caesarean Birth. Green-top Guideline No. 45. London: RCOG;2015(45).

9. Barger MK, Dunn JT, Bearman S, DeLain M, Gates E. A survey to access to trial of labour in California hospitals in 2012.BMC Preg Childbirth. 2013; 13(1):83

10. Leeman LM,Beagle M,Espey E, Ogburn T,Skipper B et al.Diminshing availability of trial of labour after Caesarean delivery in New Mexico hospitals.Obstet Gynecol. 2013;122(2):242.

11. McMahon MJ, Luther ER, Bowes WA Jr, Olshan AF. Comparison of trial of labour with an elective second Caesarean section.N Engl J Med. 1996; 335(10):68995 .

12. American College of Obstetricians and Gynecologists.Vaginal Birth after Caesarean delivery. Practice Bulletin No. 184, Obstet Gynecol. 2017;130(5):e217-33

13. American College of Obstetricians and GynecologistsVaginal birth after previous Caesarean delivery. Practice bulletin no. 115: Obstet Gynecol 2010;116(2 Pt 1):450-63.

14. Cunningham FG, Levono KJ, Bloom SL, Dashe JS, Hoffman BL, Casey BM, et al. Prior Caesarean Delivery. Williams Obstetrics 25th ed. McGraw-HILL; New Delhi: 2018:899-918.

15. Raja JF, Bangash KT, Mahmud G. VBAC Scoring: Successful vaginal delivery in previous one caesarean section in induced labour. $\mathrm{J}$ Pak Med Assoc. 2013;63(9):1147-51

16. Doshi HU, Jain RK, Vazirani AA. Prognostic factors for successful vaginal birth after caesarean section Analysis of 162 cases. J Obstet Gynecol India. 2010; 60(6):498-502.

17. Landon MB, Leindecker S, Spong CY, Hauth JC, Bloom S, Varner MW, et al. National Institute of Child Health and Human Development Maternal-Fetal Medicine Units Network. The MFMU Caesarean Registry: factors affecting the success of trial of labour after previous Caesarean delivery. Am J Obstet Gynecol. 2005;193(3):1016-23.

18. Wing DA, Paul RH: Vaginal birth after Caesarean section. selection and management. Clin Obstet Gynecol. 1999;42(4):836.

19. Peaceman AM, Gersnoviez R, Landon MB, Spong CY, Leveno KJ, Varner MW, et al. The MFMU Caesarean registry: impact of fetal size on trial of labour success for patients with previous caesarean for dystocia. Am J Obstet Gynecol 2006;195(4):1127.

20. Huang WH, Nakashima DK, Rumney PJ, Keegan KA $\mathrm{Jr}$, Chan K. Interdelivery interval and the success of vaginal birth after Caesarean delivery Obstet and Gynecol. 2002;99(1):41-4.

21. Bujold E, Gauthier RJ. Risk of uterine rupture associated with an Interdelivery interval between 18 and 24 months. Obstet Gynecol. 2010; 115(5):1003-6.

22. Kessous R, Sheiner E. Is there an association between short interval from previous Caesarean section and adverse obstetric and perinatal outcome? J Matern Fetal Neonatal Med. 2013; 26(10):1003-6.

23. Guise JM, Eden K, Emeis C, Denman MA, Marshall N, $\mathrm{Fu} \mathrm{R}$, et al. Vaginal Birth after Caesarean: New Insights. Evidence Reports/ Technology Assessments, No. 191. Rockville, Maryland, USA: Agency for Healthcare Research and Quality; 2010(191);1.

24. Dekker GA, Chan A, Luke CG, Priest K, Riley M, Halliday $\mathbf{J}$, et al. Risk of uterine rupture in Australian women attempting vaginal birth after one prior caesarean section: a retrospective population-based cohort study. BJOG 2010;117(11):1358-65.

25. Fitzpatrick KE, Kurinczuk JJ, Alfirevic Z, Spark P, Brocklehurst P, Knight M. Uterine rupture by intended mode of delivery in the UK: a national case-control study. PLoS Med 2012;9(3):e1001184.

26. Kaur G, Singh S. To study the maternal and perinatal outcome following vaginal birth after caesarean section after one previous lower segment caesarean section. Int J Reprod Contracep Obstet Gynaecol. 2015;4(3):65863.

27. Thapsamuthdechakorn A, Sekararithi R, Tongsong T. Factors Associated with Successful Trial of Labour after Caesarean Section: A Retrospective Cohort Study. J Preg. 2018(2):1-5.

28. Jain R.Safety of vaginal birth after single previous lower segment caesarean: a retrospective analysis of 200 cases. Int J Reprod Contracept Obstet Gynecol 2018;7(7):2596-602.

29. Mishra N, Taori N, Misri A. Fetomaternal outcome of pregnancy with previous Caesarean section. J Evolution Med and Dent Sci. 2014;3(47):11369-78.

30. Rossi AC, D'Addario V. Maternal morbidity following a trial of labour after Caesarean section vs elective repeat Caesarean delivery: a systematic review with metaanalysis. Am J Obstet Gynecol. 2008;199(3):22431.

31. Hammad IA, Chauhan SP, Magann EF, Abuhamad AZ.Peripartum complications with Caesarean delivery: a review of Maternal-Fetal Medicine Units Network publications. J Matern Fetal Neonatal Med 2014;27(5):463-74.

32. Crowther CA, Dodd JM, Hiller JE, Haslam RR, Robinson JS. Birth After Caesarean Study Group. Planned vaginal birth or elective repeat caesarean: patient preference restricted cohort with nested randomized trial. PLoS Med. 2012;9(3):e1001192.

Cite this article as: Manjappa AA, Subrahmanian SR. Obstetrical outcome in post caesarean pregnancy. Int J Reprod Contracept Obstet Gynecol 2018;7:4561-8. 